\title{
Developments in the management and treatment of pulmonary embolism
}

\author{
Rachel Limbrey ${ }^{1}$ and Luke Howard ${ }^{2}$
}

\begin{abstract}
Affiliations: ${ }^{1}$ University Hospital Southampton NHS Foundation Trust, Southampton, UK. ${ }^{2}$ Hammersmith Hospital, Imperial College Healthcare NHS Trust, London, UK.
\end{abstract}

Correspondence: Rachel Limbrey, CG89 Mailpoint 52, G level West Wing, Southampton General Hospital, Tremona Road, Southampton, Hampshire, S016 6YD, UK. E-mail: rachellimbreyladoctors.org.uk

ABSTRACT Pulmonary embolism (PE) is a serious and costly disease for patients and healthcare systems. Guidelines emphasise the importance of differentiating between patients who are at high risk of mortality (those with shock and/or hypotension), who may be candidates for thrombolytic therapy or surgery, and those with less severe presentations. Recent clinical studies and guidelines have focused particularly on risk stratification of intermediate-risk patients. Although the use of thrombolysis has been investigated in these patients, anticoagulation remains the standard treatment approach. Individual risk stratification directs initial treatment. Rates of recurrence differ between subgroups of patients with PE; therefore, a review of provoking factors, along with the risks of morbidity and bleeding, guides the duration of ongoing anticoagulation. The direct oral anticoagulants have shown similar efficacy and, in some cases, reduced major bleeding compared with standard approaches for acute treatment. They also offer the potential to reduce the burden on patients and outpatient services in the post-hospital phase. Rivaroxaban, dabigatran and apixaban have been shown to reduce the risk of recurrent venous thromboembolism versus placebo, when given for $>12$ months. Patients receiving direct oral anticoagulants do not require regular coagulation monitoring, but follow-up, ideally in a specialist PE clinic in consultation with primary care providers, is recommended.

0

@ERSpublications

Direct oral anticoagulants have the potential to improve management of patients with pulmonary embolism http://ow.ly/NV7K6

\section{Introduction}

Pulmonary embolism (PE) is a well-recognised and significant cause of morbidity and mortality, estimated to be associated with more than 300000 deaths per year in Europe alone [1]. Many fatal cases are not diagnosed pre mortem because of the nonspecific clinical symptoms with which patients often present [2]. In nonfatal cases, PE is associated with a risk of recurrent venous thromboembolism (VTE) (i.e. deep vein thrombosis (DVT) or PE) [3] and the development of complications such as chronic thromboembolic pulmonary hypertension (CTEPH), which, although uncommon, is associated with a relatively high morbidity and mortality rate [4]. DVT, which often accompanies PE [5], leads to post-thrombotic syndrome in up to $50 \%$ of patients within 1 year, substantially compromising quality of life [6]. PE also carries a substantial economic burden. A recent analysis in Germany calculated the cost of the first year of PE treatment to be in excess of $€ 20000$ [7].

Several clinical bodies have developed guidelines for the management of PE $[8,9]$, and an update to the 2008 European Society of Cardiology (ESC) guidelines has recently been published [2, 10]. Much of the guidance in the public domain predates the availability of direct oral anticoagulants (OACs) that now provide an alternative to the standard therapy of low molecular weight heparins (LMWHs) and vitamin K

Received: Aug 132014 | Accepted after revision: Nov 132014

Conflict of interest: Disclosures can be found alongside the online version of this article at err.ersjournals.com

Provenance: Submitted article, peer reviewed.

Copyright CERS 2015. ERR articles are open access and distributed under the terms of the Creative Commons Attribution Non-Commercial Licence 4.0. 
antagonists (VKAs). New data on the direct OACs rivaroxaban, apixaban, edoxaban and dabigatran are rapidly emerging, with rivaroxaban, dabigatran and apixaban now approved in Europe and the USA for the treatment and secondary prevention of recurrent DVT and PE in adults.

This review summarises the challenges and recent developments in the management and treatment of PE, with an emphasis on individual risk stratification and recurrence risk, and discusses the potential implications of the direct OACs for clinical practice.

\section{Diagnosis and risk stratification of PE \\ Clinical signs and symptoms and prognostic risk stratification}

The ESC guidelines for the diagnosis of clinically suspected PE are shown in figure 1. The clinical signs and symptoms of PE may be nonspecific [11], and diagnostic confirmation using imaging and laboratory tests is required $[2,12]$. Dyspnoea, tachypnoea, chest pain, cough, haemoptysis, tachycardia, syncope and respiratory crepitations are all common symptoms of $\mathrm{PE}$, but none is unique to the condition $[2,11,13]$. Even large emboli may be asymptomatic, but syncope or near-syncope, hypotension, extreme hypoxaemia, electromechanical dissociation or cardiac arrest is suggestive of a massive or "high-risk" PE [11].

The 2008 ESC guidelines suggested that PE severity should be expressed as an individual estimate of PE-related early mortality risk rather than anatomical burden and distribution. PE can be stratified by risk of early death (defined as in-hospital or 30-day mortality) based on the presence of risk markers. These include shock or hypotension, signs of right ventricular dysfunction and biochemical markers of myocardial injury. Haemodynamically unstable patients have a $>15 \%$ risk of death in the first 30 days after hospitalisation [2]. Those without shock or hypotension but with signs of right ventricular dysfunction or myocardial injury are at intermediate risk and have a 3-15\% risk of 30-day mortality. The absence of all these clinical parameters is consistent with a low-risk PE and confers a 30 -day mortality risk of $<1 \%$ [2]. According to the updated 2014 ESC guidelines, the simplified pulmonary embolism severity index (PESI) is also recommended as a means of distinguishing between patients at a high risk of death from PE and those at a lower risk $[10,14]$.

In the 2014 recommendations, the risk-stratification algorithm has been refined for those at intermediate risk [10]. In particular, further risk stratification into "intermediate-low" and "intermediate-high" categories can be considered to further aid management strategy decisions. Patients are subclassified as intermediate-high risk if they have a clinical risk score suggestive of $\mathrm{PE}$ and are positive for signs of right ventricular dysfunction, both by imaging and by means of cardiac laboratory biomarkers indicative of myocardial injury or heart failure as a result of right ventricular dysfunction. Intermediate-low risk patients have a clinical risk score suggestive of PE but may have either one or none of these indicators for right ventricular dysfunction [10].

a)

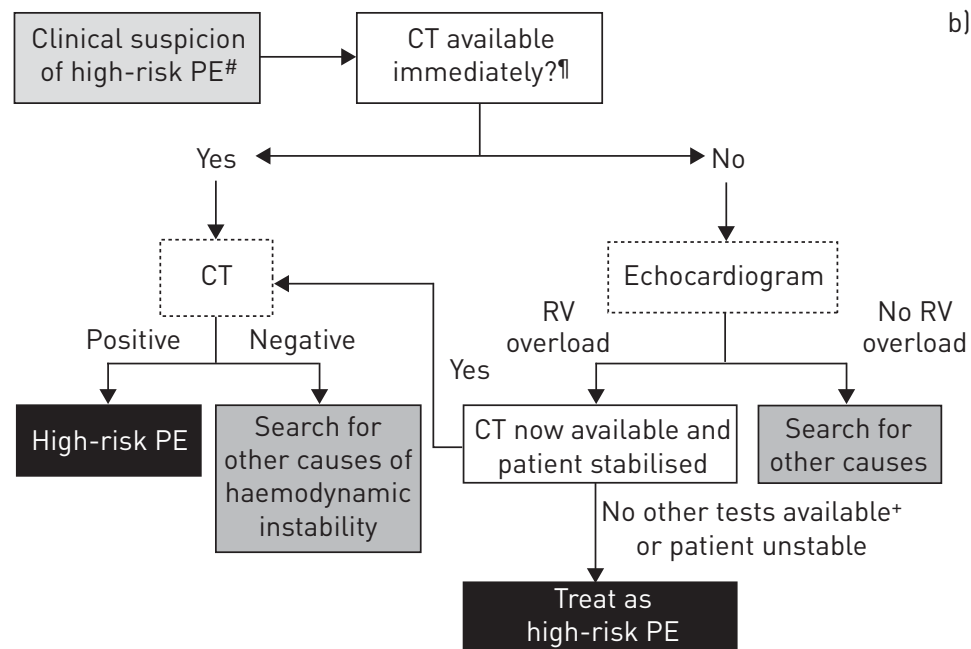

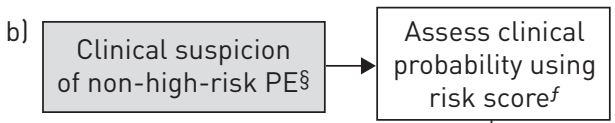
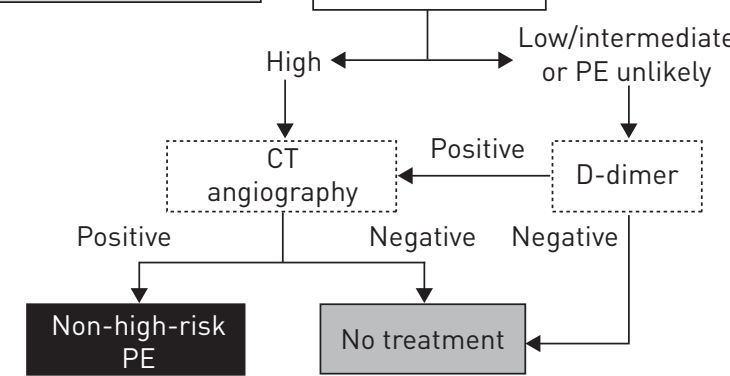

FIGURE 1 European Society of Cardiology guidelines for the diagnosis of a) clinically suspected high-risk pulmonary embolism (PE) and b) clinically suspected

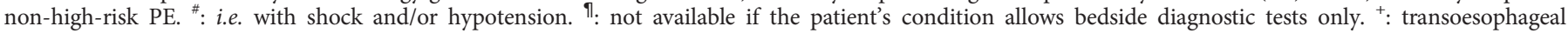

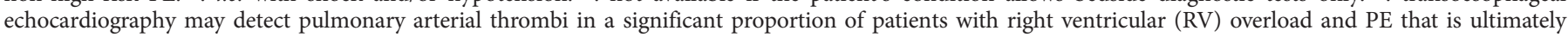
confirmed by spiral computed tomography (CT). Confirmation of deep vein thrombosis with bedside compression ultrasound could also assist

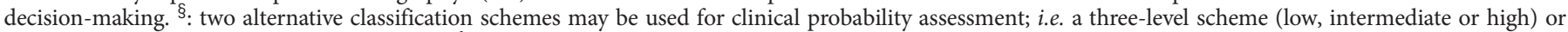
a two-level scheme (PE unlikely or PE likely). ${ }^{f}$ : e.g. Wells score. Adapted from [2] and [10]. 
To assist with identifying this substantial group of patients, Bova et al. [15] developed a prognostic model for intermediate-risk PE based on the clinical presentation and assessment of right ventricular dysfunction and myocardial injury. The primary outcome (the composite of PE-related death, haemodynamic collapse or recurrent PE within 30 days of follow-up) occurred in $6.9 \%$ of patients, and predictors of complications included a systolic blood pressure of $90-100 \mathrm{mmHg}$, elevated cardiac troponin and right ventricular dysfunction. The model identified three stages (I, II and III) associated with 30-day PE-related complication rates of $4.2 \%, 10.8 \%$ and $29.2 \%$, respectively, thereby offering clinicians a simple grading system to identify patients with intermediate-risk PE [15]. According to a recent meta-analysis, computed tomography (CT)-detected right ventricle dilation was associated with an increased 30-day all-cause mortality risk in patients with PE (OR 2.08, 95\% CI 1.63-2.66; p<0.00001), including in haemodynamically stable patients (OR 1.64, 95\% CI 1.06-2.52; $\mathrm{p}=0.03$ ), as well as an increased 30-day risk of death due to PE (OR 7.35, 95\% CI 3.59-15.09; p<0.00001). An association between right ventricle dilation and 3-month mortality rates was also observed (OR 4.65, 95\% CI 1.79-12.07; p=0.002), thus indicating that right-to-left ventricle dilation as assessed by CT angiography can be used to assess the risk of death in haemodynamically stable patients with PE [16].

\section{Confirmation of suspected high-risk (haemodynamically unstable) PE}

In haemodynamically unstable patients with a high risk of PE, diagnostic confirmation is still required [17]. Diagnosis should ideally be confirmed by CT pulmonary angiography (CTPA) [2]. Echocardiography is suggested as the preferred alternative if CTPA cannot be performed (fig. 1a) [2]. This is to confirm right ventricular overload. Evidence of acute pulmonary hypertension and right ventricular overload on the electrocardiogram of an unstable patient may be sufficient to presume high-risk PE, but only when other confirmatory tests are unavailable [2]. Levels of cardiac markers of right ventricular dysfunction (e.g. increased levels of brain natriuretic peptide) and myocardial injury (presence of troponin $\mathrm{T}$ or I) also gauge the severity of $\mathrm{PE}$ [2]. In a prospective, multicentre cohort study that included 688 patients, $\mathrm{N}$-terminal pro-brain natriuretic peptide plasma concentrations of $600 \mathrm{pg} \cdot \mathrm{mL}^{-1}$ were identified as the optimal cut-off value for the identification of elevated risk [18].

\section{Confirmation of suspected non-high-risk (haemodynamically stable) PE}

In haemodynamically stable patients, scoring systems, such as the two-level Wells score for PE (table 1) [19] and the simplified Geneva score [20], are useful for estimating the clinical probability of PE. The recommended approach for confirming or refuting non-high-risk PE is to combine a clinical probability score with D-dimer testing and CTPA where indicated (fig. 1b) [2]. In a large, prospective cohort study, this combination guided clinical management decisions effectively in $98 \%$ of cases [21]. A high-sensitivity D-dimer assay can exclude PE without further testing in $\sim 30 \%$ of cases with a low or intermediate clinical probability score $[2,22]$. In a community study, a Wells score $\leqslant 4$ combined with a negative D-dimer test safely ruled out PE in $94.5 \%$ of patients with suspected PE [23]. The combination of negative high-sensitivity D-dimer and negative CTPA equates to a $<1 \%$ likelihood of VTE [17]. In those with a high clinical probability score or an elevated D-dimer concentration despite a low or intermediate clinical probability, further investigations are required [2]. CTPA is usually recommended but is contraindicated in patients with severe renal impairment (creatinine clearance $(\mathrm{CrCl}) 15-29 \mathrm{~mL} \cdot \mathrm{min}^{-1}$ ) or allergy to contrast media, in those unable to lie flat, and is debatable in pregnancy. In these patients, ventilation-perfusion scanning may be considered [9]. Doppler ultrasound scanning of the legs should be considered as an adjunct where CTPA is contraindicated, as up to $70 \%$ of patients with symptomatic PE have a demonstrable DVT [24].

TABLE 1 Two-level Wells score for estimating the clinical probability of pulmonary embolism (PE)

Parameter

Score

Clinically suspected DVT

Alternative diagnosis less likely than PE

Rapid heart rate

Immobilisation for $>\mathbf{3}$ days or surgery within the past $\mathbf{4}$ weeks

History of VTE

Haemoptysis 1

Malignancy

After adding the total points together, a score $>6$ indicates a high probability of PE; $2-6$ a moderate probability; and <2 a low probability. The NICE 2012 guidelines suggest that a score of $>4$ points indicates PE likely and $\leqslant 4$ points indicates PE unlikely $[9,19]$. DVT: deep vein thrombosis; VTE: venous thromboembolism. 


\section{Initial treatment of PE}

Patients with high-risk PE accompanied by shock and/or hypotension are candidates to receive immediate intravenous unfractionated heparin (UFH) and thrombolytic therapy or surgical embolectomy [2, 12]. By contrast, patients with intermediate- or low-risk PE (i.e. without shock or hypotension) generally receive anticoagulant treatment, which should be initiated when PE is strongly suspected, even if the diagnostic work-up is ongoing [2,12], unless imaging can be accessed immediately [9].

There has been recent interest in thrombolytic therapy for the intermediate-risk group. In the MOPETT (Moderate Pulmonary Embolism Treated with Thrombolysis) trial, adding "low-dose" recombinant tissue plasminogen activator to anticoagulation led to earlier hospital discharge (after 2.2 days versus 4.9 days; $\mathrm{p}<0.001)$ and significantly lower composite rates of pulmonary hypertension and recurrent $\mathrm{PE}(16 \%$ versus 57\%; $\mathrm{p}<0.001)$ and composite rates of death and recurrent PE (1.6\% versus $10 \% ; \mathrm{p}=0.0489)$ at 28 months compared with anticoagulation alone, with no bleeding in either group [25]. Two small randomised studies of thrombolysis in intermediate-risk patients with PE, ULTIMA (Ultrasound Accelerated Thrombolysis of Pulmonary Embolism) (recombinant tissue plasminogen activator plus UFH compared with UFH alone) and TOPCOAT (Tenecteplase or Placebo: Cardiopulmonary Outcomes at Three Months) (tenecteplase plus LMWH compared with LMWH alone), also reported positive outcomes with thrombolytic regimens [26, 27]. In the larger randomised PEITHO (Pulmonary Embolism Thrombolysis) study, all patients were classified as intermediate-high risk according to the ESC guidelines. Patients received heparin with or without standard weight-based i.v. tenecteplase, and had a lower combined risk of mortality and haemodynamic collapse ( $2.6 \%$ versus $5.6 \%$; $=0.02)$ with thrombolysis, but also a significant increase in non-intracranial major bleeding $(6.3 \%$ versus $1.2 \% ; \mathrm{p}<0.001)$ and stroke $(2.4 \%$ versus $0.2 \% ; \mathrm{p}=0.003$ ) [28]. By day $30,2.4 \%$ and $3.2 \%$ of patients in the thrombolysis and control groups, respectively, had died $(\mathrm{p}=0.42)$.

Based on these observations, the 2014 ESC guidelines do not routinely recommend thrombolysis as primary treatment in patients with intermediate-high-risk PE; however, thrombolysis can be considered if clinical signs of haemodynamic decompensation appear [10].

The conventional treatment protocol for non-high-risk patients with PE involves initial anticoagulation with a parenteral agent, most commonly a LMWH or fondaparinux, for at least 5 days, with a VKA, often warfarin, given concurrently and starting as soon as possible. LMWH is discontinued when the international normalised ratio is stable between 2.0 and 3.0 for at least $24 \mathrm{~h}$, and the VKA dose is adjusted to remain within this range $[2,12]$. This approach balances the need for rapid initial anticoagulation and clot stabilisation, provided by LMWH, with the relative convenience of an oral agent for ongoing therapy. However, it is also relatively cumbersome and time-consuming for both patients and physicians.

Rivaroxaban, apixaban and dabigatran are approved for the treatment of PE (and DVT) and the prevention of recurrent DVT and PE in adults in Europe and the USA. The potential advantages of rivaroxaban, apixaban, edoxaban (direct factor Xa inhibitors) and dabigatran (direct thrombin inhibitor) include a similarly rapid onset of action to LMWH but with oral administration [29]. Unlike the VKAs, direct OACs offer predictable pharmacokinetic and pharmacodynamic properties and a lack of extensive drug and food interactions; therefore, removing the requirement for routine coagulation monitoring and dose adjustment (although dose reductions are specified in some cases, e.g. renal impairment) (table 2 and 3) [29-39]. However, concerns have been raised about the lack of a specific agent to reverse the effects of the direct OACs in the event of a bleeding emergency [40].

Both rivaroxaban and apixaban have been evaluated as single-drug approaches (in contrast to standard therapy) in randomised, phase III clinical trials. The EINSTEIN PE study evaluated rivaroxaban specifically for the treatment of PE [31], whereas AMPLIFY (Apixaban for the Initial Management of Pulmonary Embolism and Deep-Vein Thrombosis as First-Line Therapy) assessed outcomes with apixaban in patients with DVT and/or PE [32]. EINSTEIN PE was an open-label study that included patients with confirmed acute symptomatic PE with or without symptomatic DVT, but excluded patients scheduled to receive thrombolysis or surgery [31]. Patients received either enoxaparin $1 \mathrm{mg} \cdot \mathrm{kg}^{-1}$ twice daily, overlapping with and eventually succeeded by dose-adjusted VKA (warfarin or acenocoumarol), or single-drug rivaroxaban $15 \mathrm{mg}$ twice daily for 3 weeks followed by $20 \mathrm{mg}$ once daily. The rivaroxaban doses were chosen based on the results of dose-ranging studies [41, 42] and pharmacokinetic modelling [43], to balance the strong antithrombotic effect needed in the acute phase of treatment with the requirement to manage the risk of bleeding during longer-term therapy. Treatment continued for 3, 6 or 12 months according to each patient's clinical risk for recurrent VTE and bleeding [31]. Bleeding was defined as major if it was associated with $\mathrm{a} \geqslant 2 \mathrm{~g} \cdot \mathrm{dL}^{-1}$ fall in haemoglobin, led to transfusion of $\geqslant 2$ units of packed red cells or whole blood, involved a critical organ or led to death. Clinically relevant bleeding encompassed major bleeding and any non-major bleeding that was considered clinically relevant (e.g. 
TABLE 2 Clinically important properties of oral anticoagulants (OACs) with reference to phase III venous thromboembolism (VTE) treatment studies [30-34] and published pharmacology data [29, 35-39]

$\begin{array}{cccc}\begin{array}{c}\text { Rivaroxaban } \\ \text { (Xarelto; Bayer }\end{array} & \begin{array}{c}\text { Apixaban } \\ \text { (Eliquis; }\end{array} & \begin{array}{c}\text { Edoxaban } \\ \text { (Lixiana; Daiichi }\end{array} & \begin{array}{c}\text { Dabigatran } \\ \text { etexilate }\end{array} \\ \begin{array}{c}\text { HealthCare/Janssen } \\ \text { Pharmaceuticals) }\end{array} & \begin{array}{c}\text { Bristol-Myers } \\ \text { Squibb/Pfizer) }\end{array} & \text { Sankyo) } & \text { (Pradaxa; } \\ & & & \text { Boehringer } \\ \text { Ingelheim) }\end{array}$

\begin{tabular}{|c|c|c|c|c|c|}
\hline $\begin{array}{l}\text { Mechanism of } \\
\text { action }\end{array}$ & $\begin{array}{l}\text { Direct factor } \mathrm{Xa} \\
\text { inhibitor }\end{array}$ & $\begin{array}{l}\text { Direct factor } \mathrm{Xa} \\
\text { inhibitor }\end{array}$ & $\begin{array}{l}\text { Direct factor } \mathrm{Xa} \\
\text { inhibitor }\end{array}$ & $\begin{array}{l}\text { Direct thrombin } \\
\text { inhibitor }\end{array}$ & Vitamin $\mathrm{K}$ antagonist \\
\hline $\begin{array}{l}\text { Currently } \\
\text { approved for VTE } \\
\text { treatment in Europe } \\
\text { and the USA? }\end{array}$ & Yes & Yes & No & Yes & Yes \\
\hline $\begin{array}{l}\text { Time to maximum } \\
\text { concentration } \mathrm{h}\end{array}$ & $2-4$ & $3-4$ & $1-2$ & $0.5-2$ & Several days \\
\hline Half-life $h$ & $5-13$ & $\sim 12$ & $8-10$ & $12-14$ & $\sim 40$ \\
\hline $\begin{array}{l}\text { Proportion of } \\
\text { unchanged drug } \\
\text { excreted renally } \%\end{array}$ & $33^{\#}$ & 27 & 35 & 85 & Minor only \\
\hline $\begin{array}{l}\text { VTE treatment } \\
\text { approach and dose }\end{array}$ & $\begin{array}{l}\text { Single drug; } 15 \mathrm{mg} \\
\text { twice daily for } \\
3 \text { weeks, then } 20 \mathrm{mg} \\
\text { once daily }\end{array}$ & $\begin{array}{l}\text { Single drug; } \\
10 \mathrm{mg} \text { twice daily } \\
\text { for } 7 \text { days, then } \\
5 \mathrm{mg} \text { twice daily }\end{array}$ & $\begin{array}{c}\text { Dual drug; after median } \\
7 \text { days of parenteral } \\
\text { anticoagulation, } 60 \mathrm{mg} \\
\text { once daily }\end{array}$ & $\begin{array}{l}\text { Dual drug; after } \\
5-10 \text { days of } \\
\text { parenteral } \\
\text { anticoagulation, } \\
150 \text { mg twice daily }\end{array}$ & $\begin{array}{c}\text { Dual drug; start } \\
\text { alongside parenteral } \\
\text { anticoagulant, } \\
\text { discontinue latter after } \\
\geqslant 5 \text { days when INR } \geqslant 2 \\
\text { for } \geqslant 2 \text { days, adjust } \\
\text { dose to maintain INR } \\
2-3\end{array}$ \\
\hline $\begin{array}{l}\text { Dose adjustments for } \\
\text { VTE treatment }\end{array}$ & None & $\begin{array}{l}\text { No reduced dose } \\
\text { tested in phase III } \\
\text { trials }\end{array}$ & $\begin{array}{l}30 \mathrm{mg} \text { once daily tested } \\
\text { in patients with } \mathrm{CrCl} \\
30-50 \mathrm{~mL} \cdot \mathrm{min}^{-1} \text { or body } \\
\text { weight } \leqslant 60 \mathrm{~kg} \text { or } \\
\text { receiving concomitant } \\
\text { strong } \mathrm{P} \text {-gp inhibitors }\end{array}$ & $\begin{array}{l}\text { No reduced dose } \\
\text { tested in phase III } \\
\text { trials }\end{array}$ & $\begin{array}{c}\text { Frequent, guided by } \\
\text { the INR }\end{array}$ \\
\hline $\begin{array}{l}\text { Incidence of clinically } \\
\text { relevant/major } \\
\text { bleeding in VTE } \\
\text { treatment studies \% }\end{array}$ & $\begin{array}{c}10.3 / 1.1 \\
\text { (EINSTEIN PE) and } \\
8.1 / 0.7 \\
\text { (EINSTEIN DVT) as a } \\
\text { single drug }\end{array}$ & $\begin{array}{l}\text { 4.3/0.6 (AMPLIFY) } \\
\text { as a single drug }\end{array}$ & $\begin{array}{l}8.5 / 1.4 \text { (Hokusai-VTE) } \\
\text { after parenteral } \\
\text { induction }\end{array}$ & $\begin{array}{l}\text { 5.6/1.6 (RE-COVER) } \\
\text { after parenteral } \\
\text { induction }\end{array}$ & $\begin{array}{c}\text { Up to } 11.4 / 2.2 \text { in } \\
\text { studies of direct OACs } \\
\text { after parenteral } \\
\text { induction }\end{array}$ \\
\hline $\begin{array}{l}\text { Reversal in bleeding } \\
\text { emergency }\end{array}$ & \multicolumn{4}{|c|}{$\begin{array}{r}\text { PCC, aPCC or rFVIla suggested for rivaroxaban, apixaban and dabigatran } \\
\text { (specific antidotes in development) }\end{array}$} & $\mathrm{PCC}$ (vitamin $\mathrm{K}$ is slow) \\
\hline Food effect & $\begin{array}{l}\text { No interactions; take } \\
\text { rivaroxaban } 15 \mathrm{mg} \\
\text { and } 20 \mathrm{mg} \text { doses } \\
\text { with food }\end{array}$ & \multicolumn{3}{|c|}{$\begin{array}{l}\text { No interaction; apixaban, edoxaban and dabigatran can } \\
\text { be taken with or without food }\end{array}$} & $\begin{array}{c}\text { Affected by many } \\
\text { common foods, e.g. } \\
\text { cranberry juice and } \\
\text { vegetables containing } \\
\text { high levels of vitamin } \mathrm{K}\end{array}$ \\
\hline $\begin{array}{l}\text { Relevant drug } \\
\text { interactions }\end{array}$ & \multicolumn{3}{|c|}{$\begin{array}{c}\text { Factor Xa inhibitors: strong inhibitors of CYP3A4 and P-gp: azole } \\
\text { antimycotics (e.g. ketoconazole) and HIV protease inhibitors } \\
\text { (e.g. ritonavir) }\end{array}$} & $\begin{array}{l}\text { Dabigatran: strong } \\
\text { P-gp inhibitors and } \\
\text { inducers }\end{array}$ & Multiple \\
\hline
\end{tabular}

Contraindicated/not recommended conditions are listed in table 3. INR: international normalised ratio; CrCl: creatinine clearance; P-gp: P-glycoprotein; PCC: prothrombin complex concentrate; aPCC: activated prothrombin complex concentrate; rFVlla: recombinant activated factor VII; CYP3A4: cytochrome P450 3A4. ${ }^{\#}$ : $33 \%$ is also excreted renally as inactive metabolites.

requiring an unscheduled medical contact or procedure, temporary cessation of study drug, or associated with pain or impairment of daily activities).

At baseline, $\sim 25 \%$ of patients in EINSTEIN PE had an embolus involving multiple lobes and more than one-quarter of the pulmonary vasculature, and a similar proportion had confirmed DVT in addition to the PE. Rivaroxaban was noninferior to enoxaparin/VKA for the incidence of recurrent symptomatic VTE ( $2.1 \%$ versus $1.8 \%$, hazard ratio (HR) $1.12,95 \%$ CI $0.75-1.68 ; \mathrm{p}=0.003$ for noninferiority) [31]. Efficacy was consistent regardless of PE severity. There was a similar incidence of clinically relevant bleeding in both treatment arms (10.3\% versus $11.4 \%$, HR $0.90,95 \%$ CI $0.76-1.07$; $\mathrm{p}=0.23)$, but a $51 \%$ relative risk reduction (RRR) in major bleeding in the rivaroxaban arm compared with standard therapy $(1.1 \%$ versus $2.2 \%$, HR 
TABLE 3 Contraindicated/not recommended conditions for use of oral anticoagulants with reference to published pharmacology data [29, 35-39]

\section{Rivaroxaban (Xarelto; Bayer HealthCare/ Janssen}

Pharmaceuticals]

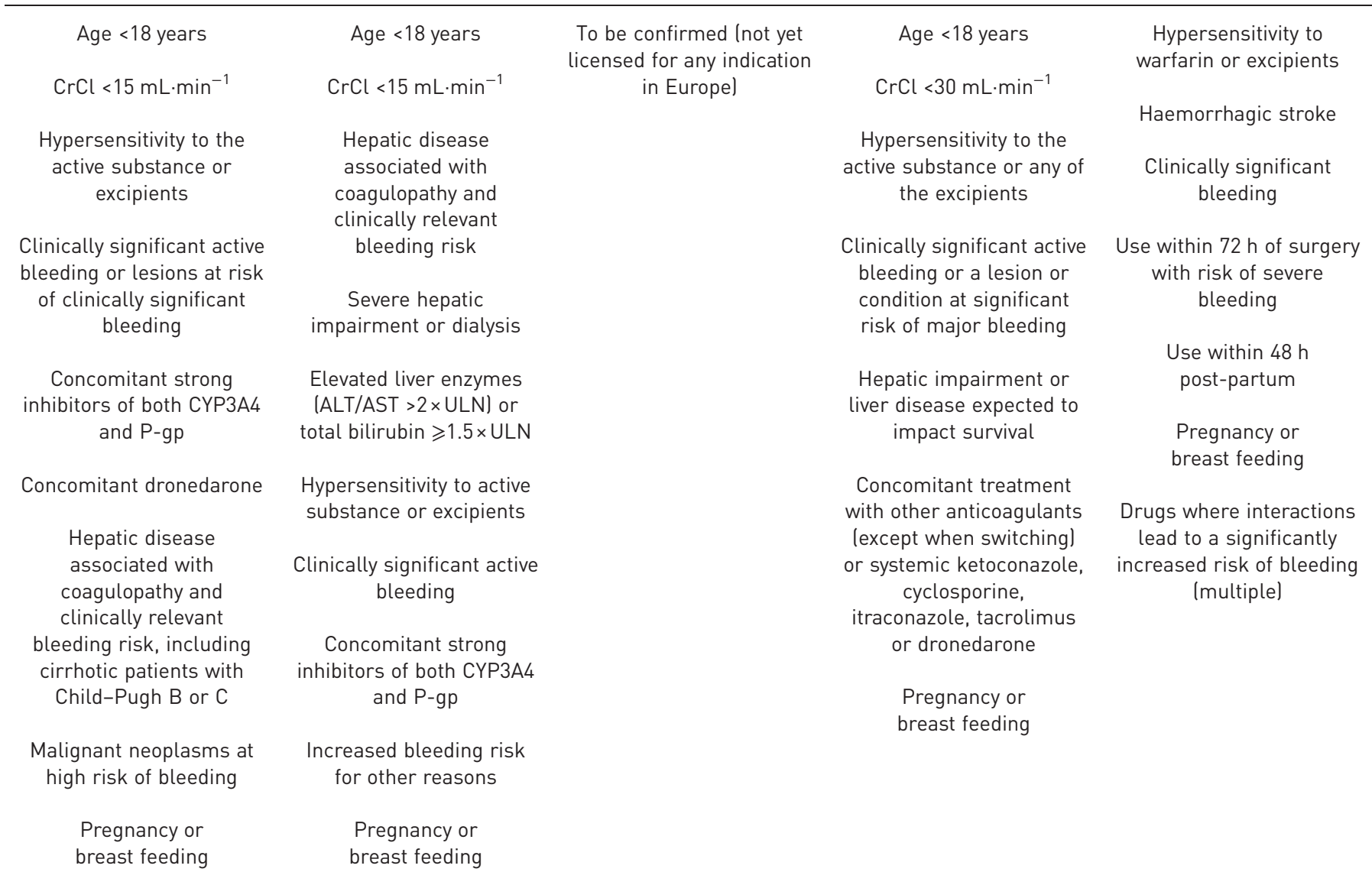

\section{Apixaban (Eliquis; Edoxaban (Lixiana; \\ Bristol-Myers Squibb/ Pfizerl Daiichi Sankyol}

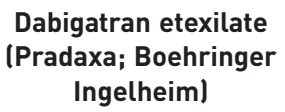

\section{Warfarin (generic)}


for the incidence of recurrent VTE or VTE-related death (2.4\% versus $2.1 \%$, HR $1.10,95 \%$ CI $0.65-1.84$; $\mathrm{p}<0.001$ for noninferiority) [33]. Major bleeding occurred with a similar incidence between the treatment arms ( $1.6 \%$ versus $1.9 \%$, HR $0.82,95 \%$ CI $0.45-1.48)$, whereas clinically relevant bleeding was significantly reduced in the dabigatran arm (5.6\% versus $8.8 \%$, HR $0.63,95 \%$ CI $0.47-0.84)$ [33]. The outcomes of a second trial, RE-COVER II, and a pooled analysis of both studies, supported these results [44].

The double-blind Hokusai-VTE study compared edoxaban, after $\geqslant 5$ days of heparin induction, with standard heparin/warfarin given for 3-12 months as judged clinically appropriate [34]. 40\% of patients had PE, and of these $\sim 46 \%$ had anatomically extensive disease. The edoxaban dose was $60 \mathrm{mg}$ once daily, but in patients with $\mathrm{CrCl} 30-50 \mathrm{~mL} \cdot \mathrm{min}^{-1}$ or body weight $\leqslant 60 \mathrm{~kg}$ or those receiving potent P-glycoprotein inhibitors (e.g. systemic ketoconazole, cyclosporin or dronedarone) the dose was reduced to $30 \mathrm{mg}$ once daily. Heparin/edoxaban was found to be noninferior to heparin/warfarin for the incidence of recurrent VTE or VTE-related death following 12 months' treatment (3.2\% versus 3.5\%, HR 0.89, 95\% CI 0.70-1.13; $\mathrm{p}<0.001$ for noninferiority) [34]. Efficacy was similar in patients with $\mathrm{PE}$ and in those who received the lower edoxaban dose. The incidence of clinically relevant bleeding events was significantly lower in the edoxaban group ( $8.5 \%$ versus $10.3 \%$, HR $0.81,95 \%$ CI $0.71-0.94 ; \mathrm{p}=0.004)$, but the incidence of major bleeding was similar to standard therapy ( $1.4 \%$ versus $1.6 \%$, HR $0.84,95 \%$ CI $0.59-1.21 ; \mathrm{p}=0.35)$ [34].

\section{Long-term prevention of recurrent VTE after an initial PE}

Patients who have had an initial PE remain at risk of recurrence without continued therapy [3, 45]. 30\% of PEs are unprovoked [2], with an associated two- to three-fold increased risk of recurrence compared with patients with an initial thromboembolism associated with risk factors [46]. Recurrence is more common in patients with persistent risk factors (e.g. cancer or elevated antiphospholipid antibodies) than in those with transient risk factors (e.g. surgery) [12, 47]. Older age, which is strongly associated with a first VTE, appears to be less influential on the risk of recurrence [48]. By contrast, although sex is not a major risk factor for initial VTE [48], men have a markedly higher risk of recurrence than women after an initial unprovoked VTE [49].

The optimal duration of anticoagulation remains uncertain. Guidelines generally suggest a minimum of 3 months, a length of treatment that is associated with a lower risk of VTE recurrence than shorter durations [46], or long term if the initial event was idiopathic or if risk factors persist (table 4) [2, 12, 46, 50-53]. Patients with CTEPH should remain on lifelong anticoagulation [54]. As yet, there are no clinical data on the effect of direct OACs on VTE-related sequelae.

Judging the benefit of continued anticoagulation in elderly patients, those with severe renal impairment, patients with cancer or those who are immobilised is particularly challenging because these factors increase the risks of both recurrent VTE and serious anticoagulant-related bleeding [12, 51, 52]. Of note, a population-based case-control study showed that patients with cancer receiving chemotherapy have an approximately six-fold increase in the adjusted (for location at VTE onset) risk ratio for VTE compared with healthy controls [55]. In patients with cancer who develop VTE, guidelines recommend LMWH over warfarin and direct OACs owing to limited data $[2,12]$. The CLOT AF trial suggested that in patients with cancer and acute VTE, dalteparin was more effective than coumarin at reducing the risk of recurrent

TABLE 4 Risk factors associated with recurrent venous thromboembolism (VTE) and anticoagulant-related bleeding $[2,12,46,50-53]$

\begin{tabular}{ccc} 
Recurrent VTE & Serious or fatal bleeding & $\begin{array}{c}\text { Both recurrent VTE and } \\
\text { serious bleeding }\end{array}$ \\
\hline Initial unprovoked VTE & Low platelet count & Increased age \\
Initial proximal DVT or PE & Previous bleeding \\
Thrombophilia & Recent major bleeding & Immobilisation \\
Residual proximal thrombosis & Previous stroke & Recent surgery (transient) \\
Male sex & Hepatic failure & Severe renal impairment \\
Elevated D-dimer concentrations & Diabetes & \\
when not receiving anticoagulation & Abnormal prothrombin time & \\
Pregnancy & Thrombocytopenia & \\
Anticoagulation lasting<3 months & Poor anticoagulant control & \\
& Comorbidity \\
& Anaemia & \\
\hline
\end{tabular}

DVT: deep vein thrombosis; PE: pulmonary embolism. 
thromboembolism without increasing the risk of bleeding [56]; however, no studies directly comparing LMWH to direct OACs are available. The 2014 ESC guidelines state that the decision for chronic anticoagulation (i.e. continuation of $\mathrm{LMWH}$, transition to VKA or discontinuation of anticoagulation) should be made on a case-by-case basis after considering the success of anticancer therapy, the estimated risk of recurrence of VTE, the bleeding risk and the preference of the patient [10]. The largest dataset of patients with cancer from studies of direct OACs for VTE treatment comes from a pooled analysis of the EINSTEIN DVT and EINSTEIN PE rivaroxaban studies. A total of 655 patients with active cancer (at baseline or diagnosed during the study) and 469 patients with a history of cancer were randomised. In patients with active cancer (diagnosed at baseline or during treatment), the incidences of recurrent VTE and clinically relevant bleeding were numerically lower in patients allocated to rivaroxaban compared with patients assigned to enoxaparin/VKA (5\% versus 7\%, HR 0.67, 95\% CI $0.35-1.30$, and $14 \%$ versus $16 \%$, HR 0.80 , 95\% CI 0.54-1.20, respectively). Patients with active cancer receiving rivaroxaban had a significantly lower incidence of major bleeding than those receiving standard therapy ( $2 \%$ versus $5 \%$, HR $0.42,95 \%$ CI $0.18-0.99$ ), whereas the incidence of all-cause death was similar between the rivaroxaban and standard therapy groups (16\% versus $18 \%$, HR $0.93,95 \%$ CI $0.64-1.35$ ). Overall, rivaroxaban showed a significant advantage compared with enoxaparin/VKA in patients with active cancer with regards to incidence of major bleeding and net clinical benefit, consistent with the overall result of the pooled analysis of the EINSTEIN DVT and EINSTEIN PE studies [57, 58].

Consideration has been given in recent guidelines to the question of whether to test patients for inherited or acquired thrombophilia, which may be a risk factor for VTE recurrence. Broadly speaking, the presence of an inherited thrombophilia is a more powerful risk factor for a first VTE than for recurrence [48]. The UK National Institute for Health and Care Excellence (NICE) guidance suggests considering testing for thrombophilia if cessation of anticoagulant treatment is planned and the patient's initial thrombosis was unprovoked, and if there is a first-degree relative who has previously sustained a DVT or PE [9]. Additionally, the ESC and European Respiratory Society recommend thrombophilia screening, including antiphospholipid (lupus anticoagulant and anticardiolipin) antibodies, in patients with CTEPH [54]. Thrombophilia testing is not recommended in patients with an initial PE with known risk factors or in those continuing anticoagulation [9].

The well-documented high incidence of major bleeding with long-term VKA therapy ( 5-9\% per annum in observational studies [59-61]) may deter long-term anticoagulation. The bleeding profile of long-term direct OAC therapy is, therefore, of great interest. Rivaroxaban, dabigatran and apixaban have all been studied in long-term secondary-prevention studies and shown favourable outcomes with treatment durations between 12 months and 3 years.

In the EINSTEIN EXT trial, rivaroxaban (20 mg once daily) was compared with placebo for 6 or 12 months in patients who had already received 6-12 months of VKA or rivaroxaban for treatment of an initial symptomatic VTE [30]. Rivaroxaban provided an $82 \%$ RRR for recurrent VTE versus placebo (incidences of $1.3 \%$ and $7.1 \%$; $<0.001)$, and the incidence of major bleeding was minimal $(0.7 \%$ of patients receiving rivaroxaban and none of those given placebo) [30].

The RE-SONATE (Twice-daily Oral Direct Thrombin Inhibitor Dabigatran Etexilate in the Long Term Prevention of Recurrent Symptomatic VTE) study found that extended dabigatran (150 mg twice daily) for patients who had received anticoagulant treatment for an initial VTE led to a 93\% RRR in the incidence of recurrent symptomatic VTE compared with placebo (incidences of $0.4 \%$ and $5.6 \%$, respectively; $\mathrm{p}<0.001$ ). Major bleeding occurred in $0.3 \%$ of those given dabigatran and in none of those given placebo [62]. In the RE-MEDY (Secondary Prevention of Venous Thrombo Embolism) study, dabigatran (150 mg twice daily) was also noninferior to warfarin as extended therapy after successful initial VTE treatment (incidence of recurrent VTE $1.8 \%$ versus $1.3 \%$; $\mathrm{p}=0.01$ for noninferiority), with a similar incidence of major bleeding (HR $0.52,95 \%$ CI 0.27-1.01) but a higher frequency of acute coronary syndrome events ( $0.9 \%$ versus $0.2 \%$; $=0.02)$ [62].

In the AMPLIFY-EXT trial, apixaban (2.5 or $5 \mathrm{mg}$ twice daily) provided an $81 \%$ RRR in recurrent VTE or VTE-related death compared with placebo $(1.7 \%$ for both apixaban doses versus $8.8 \%$; $\mathrm{p}<0.001)$ with major bleeding in $\leqslant 0.5 \%$ of patients in all treatment arms [63]. In this study, patients who had been treated for 6-12 months with standard anticoagulant therapy or had completed treatment with apixaban in the AMPLIFY trial (i.e. at a dose of $10 \mathrm{mg}$ twice daily initially for acute treatment, then $5 \mathrm{mg}$ twice daily from 7 days to 6 months) received extended anticoagulation at this dose or $2.5 \mathrm{mg}$ twice daily for a further 12 months. This type of step-down dosing for the long-term secondary prevention of VTE, which takes into account the decreasing risk of VTE recurrence over time and the need to minimise the risk of bleeding, is an attractive idea in principle.

One way of stepping down therapy is for patients to receive acetylsalicylic acid (ASA) for the long-term prevention of recurrent VTE, and this has been investigated in two randomised, double-blind studies. In 
WARFASA (the Warfarin and Aspirin Study), patients had completed 6-18 months of OAC therapy for an initial event and were then randomised to ASA $100 \mathrm{mg}$ once daily or placebo for at least another 2 years [64]. VTE recurred at a significantly lower rate in patients who received ASA (6.6\% versus $11.2 \%$ per year, HR $0.58,95 \%$ CI $0.36-0.93$ ) and only one patient in each treatment arm experienced major bleeding [64]. By contrast, in the similarly designed ASPIRE (Aspirin to Prevent Recurrent Venous Thromboembolism) study, ASA was not significantly more protective than placebo for secondary prevention of VTE in patients who had received anticoagulant treatment for an initial VTE $(p=0.09)$. Despite this, ASA did lead to a reduction in the composite rate of VTE, myocardial infarction, stroke and cardiovascular death compared with placebo $(\mathrm{p}=0.01)$, without a significant increase in major bleeding $(\mathrm{p}=0.22)[65]$.

Reduced-dose anticoagulation and the use of ASA for long-term secondary VTE prevention will be further investigated in the EINSTEIN CHOICE study, in which patients who have completed 6 or 12 months of anticoagulation treatment for initial VTE will be randomised to 12 months of further treatment with either rivaroxaban $20 \mathrm{mg}$ once daily (as in EINSTEIN EXT), rivaroxaban $10 \mathrm{mg}$ once daily or ASA $100 \mathrm{mg}$ once daily (https:/clinicaltrials.gov/ct2/show/NCT02064439). The next question will be how to determine which patients receive which treatment at which dose, most likely guided by assessment of risk factors for recurrent thrombosis and bleeding.

Based on the results of the AMPLIFY [32], EINSTEIN [58] and RE-COVER [44] studies, and subsequent approvals in Europe, the ESC now recommends apixaban $(10 \mathrm{mg}$ twice daily for 7 days followed by $5 \mathrm{mg}$ twice daily), rivaroxaban ( $15 \mathrm{mg}$ twice daily for 21 days followed by $20 \mathrm{mg}$ once daily) and dabigatran (150 mg twice daily after standard parenteral anticoagulation in the acute phase, or $110 \mathrm{mg}$ twice daily for patients $>80$ years of age or those under concomitant verapamil treatment) for the treatment and secondary prevention of VTE. Administration of edoxaban is also recommended by the ESC, based on the results of the Hokusai-VTE study [34], as an alternative to VKA treatment following acute-phase parenteral anticoagulation, despite not currently being approved in the European Union or the USA for VTE treatment. All four direct OACs have received the Class 1B level of recommendation, suggesting that they are equivalent to the established standard of care [10].

\section{Inpatient versus outpatient management of PE}

Haemodynamically unstable, high-risk PE patients will most likely present to the emergency department. However, low- and intermediate-risk patients may present to and begin anticoagulant treatment within a variety of hospital departments. This variable patient pathway has led to the emergence in several hospitals of a dedicated PE service, which may coordinate the different specialties required to confirm the diagnosis and manage ongoing treatment.

Dedicated PE services are also well placed to identify those low-risk patients who may be appropriate for outpatient care overseen by their general practitioner or an acute medical unit, and to facilitate the transition from hospital treatment to community care. The Hestia (Efficacy and safety of home treatment versus in hospital treatment with LMWH in patients with non-massive pulmonary embolism) study, which included a group of patients with asymptomatic right ventricular dysfunction on CTPA, concluded that outpatient treatment of acute PE may be effective and safe in patients selected using predefined and easy-to-use criteria, on the basis of observed low recurrence, mortality and bleeding rates [66]. With continual improvements in scanning technology, an increasing number of small pulmonary emboli are being detected, many of which are located in segmental and subsegmental vessels [67]. Clinical data have suggested that treating patients with these presentations with anticoagulants may not be necessary in the absence of cardiopulmonary compromise, concurrent DVT or persistent risk factors for recurrent VTE $[68,69]$. However, a recent analysis of 3728 patients with clinically suspected PE found a similar prevalence of VTE risk factors and 3-month risk of recurrent VTE and mortality in patients with subsegmental PE as in those with more proximal PE [70], suggesting that these presentations should be taken seriously, at least when symptoms or other factors are present. These patients could be candidates for outpatient treatment, particularly now that direct OAC treatment is an option.

Studies investigating the treatment of low-risk PE in the community have generally provided positive results; however, none has included direct OACs. An open-label, multicentre, randomised trial compared outpatient and in-hospital treatment of 344 patients with low-risk PE as judged by the PESI score [71]. Only one outpatient had recurrent VTE within 90 days (versus no inpatients; $\mathrm{p}=0.011$ for noninferiority) and three had major bleeding (compared with no inpatients; $\mathrm{p}=0.086$ ); one patient in each group died. Retrospective analyses conducted in Ireland [72] and Canada [73, 74] also support the concept of outpatient treatment of low-risk PE. The largest dataset comes from a meta-analysis of published studies, in which Zondag et al. [75] compared outcomes in 1657 patients with low-risk PE treated either entirely in hospital, discharged within $72 \mathrm{~h}$ or treated solely as outpatients. There was no statistical difference in 
the incidence of recurrent VTE (1.1-1.7\%), major bleeding (0.8-1.0\%) or mortality (0.7-2.3\%) among the three patient groups [75]. The incidence of mortality among outpatients was $1.9 \%$, but this decreased to $0.6 \%$ when studies with an over-representation of patients with cancer were excluded. However, a Spanish study that randomised patients with PE to early discharge or inpatient care was stopped early because of an unexpectedly high short-term mortality rate in the early-discharge group, despite the patients included being deemed low risk [76].

A number of centres have now established outpatient PE services, often working with acute medical units and haematology departments to aid the streamlining of patients undergoing investigation for possible PE and to manage ongoing outpatient care. The organisation and functioning of such a multidisciplinary system is challenging, and the relevant specialist departments must be actively involved in drawing up patient pathways and following standard procedures. Collaboration between specialties is vital.

Dedicated PE follow-up clinics can review the severity of PE sustained, and any ongoing right heart injury and subsequent pulmonary hypertension. Up to $50 \%$ of patients with PE will have signs of right heart strain at presentation [2, 77]. PENGo et al. [4] suggested that up to $4 \%$ of such patients go on to develop pulmonary hypertension at 2 years. They did not see any significant additional increase in cases after this time.

In PE clinics, provoking factors can be assessed, ongoing risk determined and advice on length of anticoagulation provided. The clinical utility of thrombophilia testing can be discussed and offered if deemed helpful. For patients with coexistent DVT, legs can be assessed for post-thrombotic syndrome and the use of compression stockings discussed. Current evidence does not show any benefit for above-knee stockings compared with those that extend to below the knee [78]. Compression stockings are recommended to be worn for 2 years after a DVT and for longer if signs of venous insufficiency persist [8]. However, the recently reported 2-year SOX trial (Compression Stockings to Prevent the PostThrombotic Syndrome After Symptomatic Proximal Deep Venous Thrombosis) did not find a benefit for stockings over placebo for prevention of post-thrombotic syndrome after a first proximal DVT [79].

Finally, when anticoagulant therapy has been completed, advice can be given regarding lessening an individual's risk of recurrent thrombosis during future high-risk scenarios, e.g. long-haul flights ( $4 \mathrm{~h}$ or longer). In this case, those who have sustained a minor provoked PE might be advised, in addition to standard advice on the use of compression stockings and the maintenance of hydration and mobility, to consider a prophylactic dose of LMWH prior to each leg of a flight [80]. This mode of management is in line with the current model of personalised medicine.

\section{Developments in the management and treatment of PE: implications for clinical practice}

The development of direct OACs for ongoing anticoagulant treatment provides an opportunity to simplify anticoagulation management and facilitate the transition from inpatient to outpatient care. Fixed doses for treatment, coupled with predictable pharmacokinetics and pharmacodynamics regardless of demographic factors, obviate the requirement for routine coagulation monitoring and dose adjustment [29]. Of the direct OACs currently licensed for VTE treatment, rivaroxaban provides the option of using a single oral drug from treatment initiation for the total duration of anticoagulation, whereas dabigatran is licensed for use after standard heparin induction. Both approaches have been shown to be effective for the treatment of initial VTE and for long-term secondary prevention [30, 31, 33, 62]. Rivaroxaban has also been tested successfully for the specific treatment of PE [31].

Against this, limitations such as the lack of specific reversal agents for bleeding emergencies must be considered [40]. However, it is important to note that acute treatment trials showed that direct OACs did not increase the incidence of major bleeding compared with enoxaparin/VKA (and in the case of rivaroxaban and apixaban, the risk of major bleeding was decreased) [30-34], and that there was no substantial increase in major bleeding with direct OACs versus placebo in long-term extension studies $[30,62,63]$. Nevertheless, concern remains regarding those rare incidences in which immediate reversal may be required. In bleeding emergencies in patients taking direct OACs, standard strategies should be implemented with consideration of pro-haemostatic agents such as prothrombin complex concentrate. Newly developed specific reversal agents for direct factor $\mathrm{Xa}$ and thrombin inhibitors are under investigation [40, 81, 82]. For non-life-threatening bleeding, temporary or permanent treatment discontinuation may be sufficient, particularly given the short half-life of the direct OACs (5-17 h) [83] compared with, for example, warfarin (20-60 h) [39].

The initial upfront costs of direct OACs are higher than those of enoxaparin/VKA therapy, but in the UK, NICE concluded that rivaroxaban was cost-effective for VTE treatment on the basis of the decreased use of healthcare resources for coagulation monitoring [84]. Although the use of direct OACs should ease the burden on community services, it may also provide fewer opportunities for physicians to monitor patient compliance and wellbeing. Specialist PE clinics, engaging with primary-care physicians, will assess 
response to treatment and requirement for longer-term anticoagulation. A potential protocol for the stratified treatment of patients with PE is presented in figure 2. Outpatient treatment with direct OACs will be possible for many patients, and it may be particularly appropriate for those who cannot tolerate warfarin or those for whom dose adjustments with VKAs may be particularly burdensome (e.g. the elderly). Additionally, the increasing sensitivity of imaging techniques may lead to identification of a larger number of cases of low-risk PE, and these patients may be suitable for early discharge; direct OACs may facilitate the transition from hospital to home in this scenario.

Haemodynamically unstable patients and those with $\mathrm{CrCl}<15 \mathrm{~mL} \cdot \mathrm{min}^{-1}\left(<30 \mathrm{~mL} \cdot \mathrm{min}^{-1}\right.$ for dabigatran) are not appropriate for treatment with direct OACs. There are also limited data in patients with $\mathrm{CrCl} 15-$ $29 \mathrm{~mL} \cdot \mathrm{min}^{-1}$ (not included in phase III trials) and those with cancer (of whom there were few in these studies) [30-34]. Patients with complications such as CTEPH may be candidates for direct OAC treatment, but should be referred to a specialist centre [54]. If a patient is not considered appropriate for, or does not wish to continue, long-term anticoagulant treatment, ASA could be considered for extended secondary prevention of VTE. However, data on its efficacy are equivocal and the magnitude of the protective effect appears more modest ( 40\% RRR in recurrent VTE versus placebo) [64,65] than that with the direct OACs $(\sim 80-90 \%$ RRR) [30, 62, 63]. Further studies in this area are ongoing.

In addition to providing an important further option for the management of PE, direct OACs are already in use in other settings, including VTE prophylaxis after major orthopaedic surgery, stroke prevention in patients with nonvalvular atrial fibrillation and, in the case of rivaroxaban, prevention of cardiovascular events in patients with acute coronary syndrome. Increasing use will provide us with information on the currently unknown pitfalls as well as the advantages of these new, direct OACs.

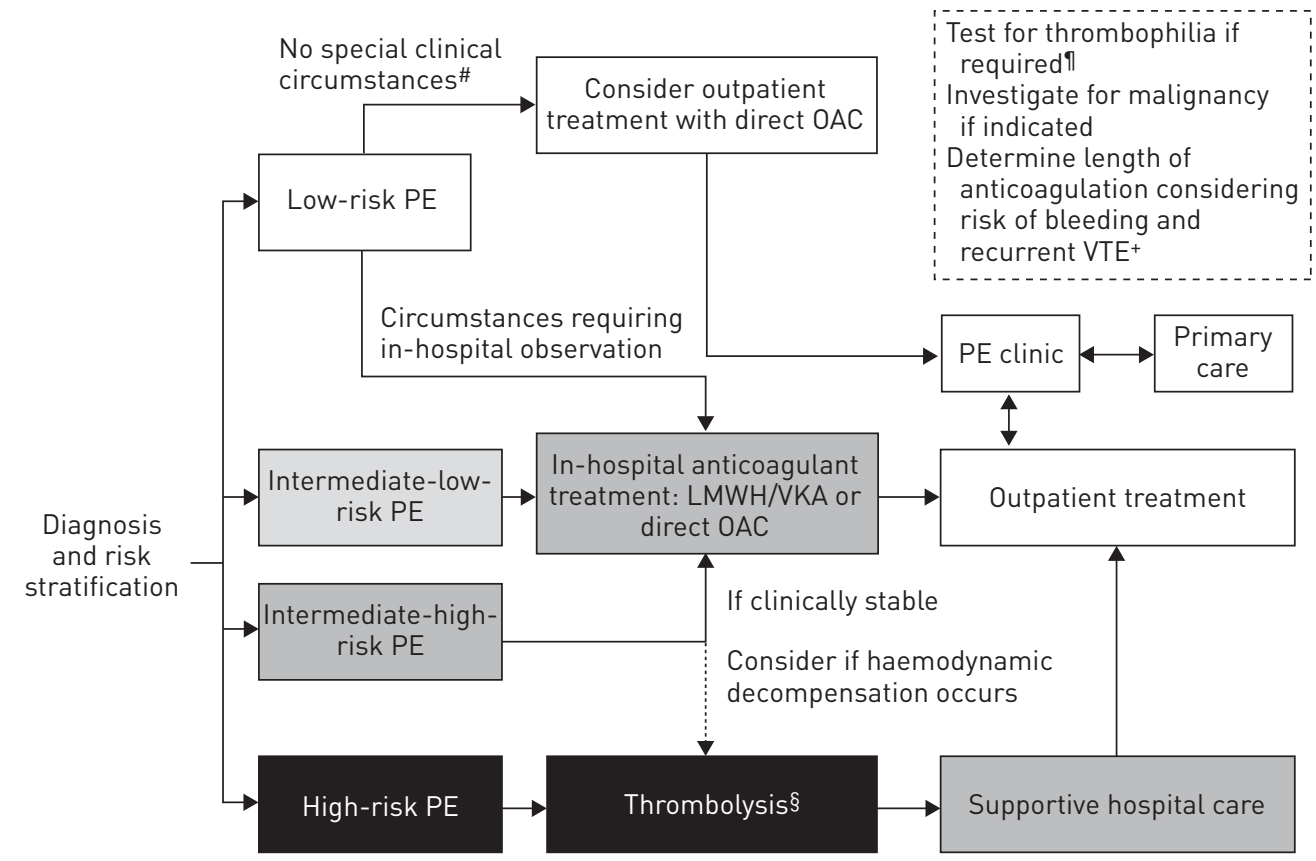

FIGURE 2 Potential protocol for the treatment of pulmonary embolism (PE), incorporating direct oral anticoagulants (OACs). Risk groups correspond to the European Society of Cardiology guidelines for stratification by 30-day mortality risk, i.e. high-risk PE: patient is haemodynamically unstable (high risk of death; calculation of clinical risk score not necessary); intermediate-high-risk PE: patient is without shock or hypotension but has a clinical risk score suggestive of $\mathrm{PE}$ and indicative of high 30-day mortality risk (Pulmonary Embolism Severity Index (PESI) class III-V/simplified (s) PESI $\geqslant 1$ point), and is positive for both signs of right ventricular (RV) dysfunction on an imaging test and by means of cardiac laboratory biomarkers indicative of myocardial injury or heart failure as a result of RV dysfunction; intermediate-low-risk PE: patient is without shock or hypotension but has a clinical risk score suggestive of PE (PESI I-II or III-IV/sPESI $\geqslant 0$ ) and may have either one or none of the indicators for RV dysfunction; low-risk PE: patient is without shock or hypotension, has PESI I-II/sPESI=0, and no signs of RV dysfunction [10]. LMWH: low molecular weight heparin; VKA: vitamin $\mathrm{K}$ antagonist. ": may include patients with subsegmental PE; ": patient has initial unprovoked thrombosis, has a first-degree relative with a history of venous thromboembolism (VTE) or has chronic thromboembolic pulmonary hypertension; ${ }^{+}$: consider use of clinical risk scores to guide decision; ${ }^{\S}$ : high-risk patients receiving thrombolysis are not recommended to receive direct OACs, and these patients were excluded from clinical trials of direct OACs for VTE treatment. 


\section{Acknowledgements}

The authors would like to acknowledge Stephen Purver (Chameleon Communications International, London, UK), who provided editorial support for this manuscript with funding from Bayer HealthCare Pharmaceuticals and Janssen Scientific Affairs, LLC.

\section{References}

1 Cohen AT, Agnelli G, Anderson FA, et al. Venous thromboembolism (VTE) in Europe. The number of VTE events and associated morbidity and mortality. Thromb Haemost 2007; 98: 756-764.

2 Torbicki A, Perrier A, Konstantinides S, et al. Guidelines on the diagnosis and management of acute pulmonary embolism: the Task Force for the Diagnosis and Management of Acute Pulmonary Embolism of the European Society of Cardiology (ESC). Eur Heart J 2008; 29: 2276-2315.

3 Eichinger S, Weltermann A, Minar E, et al. Symptomatic pulmonary embolism and the risk of recurrent venous thromboembolism. Arch Intern Med 2004; 164: 92-96.

4 Pengo V, Lensing AWA, Prins $\mathrm{MH}$, et al. Incidence of chronic thromboembolic pulmonary hypertension after pulmonary embolism. N Engl J Med 2004; 350: 2257-2264.

5 Mohr DN, Silverstein MD, Heit JA, et al. The venous stasis syndrome after deep venous thrombosis or pulmonary embolism: a population-based study. Mayo Clin Proc 2000; 75: 1249-1256.

6 Baldwin MJ, Moore HM, Rudarakanchana N, et al. Post-thrombotic syndrome: a clinical review. J Thromb Haemost 2013; 11: 795-805.

7 Kröger K, Küpper-Nybelen J, Moerchel C, et al. Prevalence and economic burden of pulmonary embolism in Germany. Vasc Med 2012; 17: 303-309.

8 Guyatt GH, Akl EA, Crowther $\mathrm{M}$, et al. Executive summary: antithrombotic therapy and prevention of thrombosis, 9th ed: American College of Chest Physicians evidence-based clinical practice guidelines. Chest 2012; 141: Suppl. 2, 7S-47S.

9 National Institute for Health and Care Excellence. Venous thromboembolic diseases: the management of venous thromboembolic diseases and the role of thrombophilia testing. NICE guidelines CG144. http://guidance.nice.org. uk/CG144 Date last updated: June 2012. Date last accessed: July 222014

10 Konstantinides SV, Torbicki A, Agnelli G, et al. 2014 ESC guidelines on the diagnosis and management of acute pulmonary embolism. Eur Heart J 2014; 35: 3033-3073.

11 Tapson VF. Acute pulmonary embolism. N Engl J Med 2008; 358: 1037-1052.

12 Kearon C, Akl EA, Comerota AJ, et al. Antithrombotic therapy for VTE disease: antithrombotic therapy and prevention of thrombosis, 9th ed: American College of Chest Physicians evidence-based clinical practice guidelines. Chest 2012; 141: Suppl. 2, e419S-e494S.

13 Blann AD, Lip GYH. Venous thromboembolism. BMJ 2006; 332: 215-219.

14 Jiménez D, Aujesky D, Moores L, et al. Simplification of the pulmonary embolism severity index for prognostication in patients with acute symptomatic pulmonary embolism. Arch Intern Med 2010; 170: 1383-1389.

15 Bova C, Sanchez O, Prandoni P, et al. Identification of intermediate-risk patients with acute symptomatic pulmonary embolism. Eur Respir J 2014; 44: 694-703.

16 Becattini C, Agnelli G, Germini F, et al. Computed tomography to assess risk of death in acute pulmonary embolism: a meta-analysis. Eur Respir J 2014; 43: 1678-1690.

17 Fesmire FM, Brown MD, Espinosa JA, et al. Critical issues in the evaluation and management of adult patients presenting to the emergency department with suspected pulmonary embolism. Ann Emerg Med 2011; 57: $628-652$.

18 Lankeit M, Jiménez D, Kostrubiec M, et al. Validation of N-terminal pro-brain natriuretic peptide cut-off values for risk stratification of pulmonary embolism. Eur Respir J 2014; 43: 1669-1677.

19 Wells PS, Anderson DR, Rodger M, et al. Derivation of a simple clinical model to categorize patients probability of pulmonary embolism: increasing the models utility with the SimpliRED D-dimer. Thromb Haemost 2000; 83: 416-420.

20 Klok FA, Mos IC, Nijkeuter M, et al. Simplification of the revised Geneva score for assessing clinical probability of pulmonary embolism. Arch Intern Med 2008; 168: 2131-2136.

21 van Belle A, Büller HR, Huisman MV, et al. Effectiveness of managing suspected pulmonary embolism using an algorithm combining clinical probability, D-dimer testing, and computed tomography. JAMA 2006; 295: 172-179.

22 Segal JB, Eng J, Tamariz LJ, et al. Review of the evidence on diagnosis of deep venous thrombosis and pulmonary embolism. Ann Fam Med 2007; 5: 63-73.

23 Geersing GJ, Erkens PM, Lucassen WA, et al. Safe exclusion of pulmonary embolism using the Wells rule and qualitative D-dimer testing in primary care: prospective cohort study. BMJ 2012; 345: e6564.

24 Kearon C. Natural history of venous thromboembolism. Circulation 2003; 107: Suppl. 1, I22-I30.

25 Sharifi M, Bay C, Skrocki L, et al. Moderate pulmonary embolism treated with thrombolysis (from the "MOPETT" Trial). Am J Cardiol 2013; 111: 273-277.

26 Kucher N, Boekstegers P, Müller OJ, et al. Randomized, controlled trial of ultrasound-assisted catheter-directed thrombolysis for acute intermediate-risk pulmonary embolism. Circulation 2014; 129: 479-486.

27 Kline J, Hernandez J, Kabrhel C, et al. Randomized trial of tenecteplase or placebo with low molecular weight heparin for acute submassive pulmonary embolism: assessment of patient-oriented cardiopulmonary outcomes at three months. I Am Coll Cardiol 2013; 61: Suppl. 10, Abstract 932-8, DOI:10.1016/S0735-1097(13)62074-4.

28 Meyer G, Vicaut E, Danays T, et al. Fibrinolysis for patients with intermediate-risk pulmonary embolism. $N$ Engl J Med 2014; 370: 1402-1411.

29 Eikelboom JW, Weitz JI. New anticoagulants. Circulation 2010; 121: 1523-1532.

30 EINSTEIN Investigators. Oral rivaroxaban for symptomatic venous thromboembolism. N Engl J Med 2010; 363: 2499-2510.

31 EINSTEIN-PE Investigators. Oral rivaroxaban for the treatment of symptomatic pulmonary embolism. $N$ Engl J Med 2012; 366: 1287-1297.

32 Agnelli G, Buller HR, Cohen A, et al. Oral apixaban for the treatment of acute venous thromboembolism. $N$ Engl J Med 2013; 369: 799-808. 
33 Schulman S, Kearon C, Kakkar AK, et al. Dabigatran versus warfarin in the treatment of acute venous thromboembolism. N Engl J Med 2009; 361: 2342-2352.

34 Hokusai-VTE Investigators. Edoxaban versus warfarin for the treatment of symptomatic venous thromboembolism. N Engl J Med 2013; 369: 1406-1415.

35 Zahir H, Matsushima N, Halim AB, et al. Edoxaban administration following enoxaparin: a pharmacodynamic, pharmacokinetic, and tolerability assessment in human subjects. Thromb Haemost 2012; 108: 166-175.

36 Bayer Pharma AG. Xarelto (rivaroxaban) Summary of Product Characteristics. www.ema.europa.eu/docs/en_GB/ document_library/EPAR_-_Product_Information/human/000944/WC500057108.pdf Date last updated: May 15, 2015. Date last accessed: June 26, 2015.

37 Bristol-Myers Squibb, Pfizer EEIG. Eliquis (apixaban) Summary of Product Characteristics. www.ema.europa.eu/ docs/en_GB/document_library/EPAR___Product_Information/human/002148/WC500107728.pdf Date last updated: September 29, 2014. Date last accessed: June 26, 2015.

38 Boehringer Ingelheim International GmbH. Pradaxa (dabigatran etexilate) Summary of Product Characteristics. www.ema.europa.eu/docs/en_GB/document_library/EPAR_-_Product_Information/human/000829/WC500041059. pdf Date last updated: February 18, 2015. Date last accessed: June 26, 2015.

39 Bristol-Myers Squibb. Coumadin (warfarin sodium) Prescribing Information. http://packageinserts.bms.com/pi/ pi_coumadin.pdf Date last updated: October, 2011. Date last accessed: October 6, 2014.

40 Siegal DM, Crowther MA. Acute management of bleeding in patients on novel oral anticoagulants. Eur Heart $J$ 2013; 34: 489-498.

41 Buller HR, Lensing AWA, Prins $\mathrm{MH}$, et al. A dose-ranging study evaluating once-daily oral administration of the Factor Xa inhibitor rivaroxaban in the treatment of patients with acute symptomatic deep vein thrombosis: the Einstein-DVT Dose-Ranging Study. Blood 2008; 112: 2242-2247.

42 Agnelli G, Gallus A, Goldhaber SZ, et al. Treatment of proximal deep-vein thrombosis with the oral direct Factor Xa inhibitor rivaroxaban (BAY 59-7939): the ODIXa-DVT (Oral Direct Factor Xa Inhibitor BAY 59-7939 in patients with acute symptomatic Deep-Vein Thrombosis) study. Circulation 2007; 116: 180-187.

43 Mueck W, Lensing AWA, Agnelli G, et al. Rivaroxaban: population pharmacokinetic analyses in patients treated for acute deep-vein thrombosis and exposure simulations in patients with atrial fibrillation treated for stroke prevention. Clin Pharmacokinet 2011; 50: 675-686.

44 Schulman S, Kakkar AK, Goldhaber SZ, et al. Treatment of acute venous thromboembolism with dabigatran or warfarin and pooled analysis. Circulation 2014; 129: 764-772.

45 Douketis JD, Kearon C, Bates S, et al. Risk of fatal pulmonary embolism in patients with treated venous thromboembolism. JAMA 1998; 279: 458-462.

46 Boutitie F, Pinede L, Schulman S, et al. Influence of preceding length of anticoagulant treatment and initial presentation of venous thromboembolism on risk of recurrence after stopping treatment: analysis of individual participants' data from seven trials. BMJ 2011; 342: d3036.

47 Poli D, Miniati M. The incidence of recurrent venous thromboembolism and chronic thromboembolic pulmonary hypertension following a first episode of pulmonary embolism. Curr Opin Pulm Med 2011; 17: 392-397.

48 Lijfering WM, Rosendaal FR, Cannegieter SC. Risk factors for venous thrombosis - current understanding from an epidemiological point of view. Br J Haematol 2010; 149: 824-833.

49 Douketis J, Tosetto A, Marcucci M, et al. Risk of recurrence after venous thromboembolism in men and women: patient level meta-analysis. BMJ 2011; 342: d813.

50 Eichinger S, Heinze G, Jandeck LM, et al. Risk assessment of recurrence in patients with unprovoked deep vein thrombosis or pulmonary embolism: the Vienna prediction model. Circulation 2010; 121: 1630-1636.

51 Tosetto A, Iorio A, Marcucci M, et al. Predicting disease recurrence in patients with previous unprovoked venous thromboembolism: a proposed prediction score (DASH). J Thromb Haemost 2012; 10: 1019-1025.

52 Nieto JA, Solano R, Ruiz-Ribó MD, et al. Fatal bleeding in patients receiving anticoagulant therapy for venous thromboembolism: findings from the RIETE registry. J Thromb Haemost 2010; 8: 1216-1222.

53 Nijkeuter M, Söhne M, Tick LW, et al. The natural course of hemodynamically stable pulmonary embolism: clinical outcome and risk factors in a large prospective cohort study. Chest 2007; 131: 517-523.

54 Task Force for Diagnosis and Treatment of Pulmonary Hypertension of European Society of Cardiology (ESC), European Respiratory Society (ERS), International Society of Heart and Lung Transplantation (ISHLT). Guidelines for the diagnosis and treatment of pulmonary hypertension. Eur Respir J 2009; 34: 1219-1263.

55 Heit JA, Silverstein MD, Mohr DN, et al. Risk factors for deep vein thrombosis and pulmonary embolism: a population-based case-control study. Arch Intern Med 2000; 160: 809-815.

56 Lee AY, Levine MN, Baker RI, et al. Low-molecular-weight heparin versus a coumarin for the prevention of recurrent venous thromboembolism in patients with cancer. N Engl J Med 2003; 349: 146-153.

57 Prins MH, Lensing AWA, Brighton TA, et al. Oral rivaroxaban versus enoxaparin with vitamin $\mathrm{K}$ antagonist for the treatment of symptomatic venous thromboembolism in patients with cancer (EINSTEIN-DVT and EINSTEIN-PE): a pooled subgroup analysis of two randomised controlled trials. Lancet Haematol 2014; 1: e37-e46.

58 Prins $\mathrm{MH}$, Lensing AWA, Bauersachs $\mathrm{R}$, et al. Oral rivaroxaban versus standard therapy for the treatment of symptomatic venous thromboembolism: a pooled analysis of the EINSTEIN-DVT and PE randomized studies. Thromb J 2013; 11: 21.

59 Fihn SD, Callahan CM, Martin DC, et al. The risk for and severity of bleeding complications in elderly patients treated with warfarin. The National Consortium of Anticoagulation Clinics. Ann Intern Med 1996; 124: 970-979.

60 Beyth RJ, Quinn LM, Landefeld CS. Prospective evaluation of an index for predicting the risk of major bleeding in outpatients treated with warfarin. Am J Med 1998; 105: 91-99.

61 McMahan DA, Smith DM, Carey MA, et al. Risk of major hemorrhage for outpatients treated with warfarin. J Gen Intern Med 1998; 13: 311-316.

62 Schulman S, Kearon C, Kakkar AK, et al. Extended use of dabigatran, warfarin, or placebo in venous thromboembolism. N Engl J Med 2013; 368: 709-718.

63 Agnelli G, Buller HR, Cohen A, et al. Apixaban for extended treatment of venous thromboembolism. $N$ Engl J Med 2013; 368: 699-708.

64 Becattini C, Agnelli G, Schenone A, et al. Aspirin for preventing the recurrence of venous thromboembolism. N Engl J Med 2012; 366: 1959-1967. 
65 Brighton TA, Eikelboom JW, Mann K, et al. Low-dose aspirin for preventing recurrent venous thromboembolism. N Engl J Med 2012; 367: 1979-1987.

66 Zondag W, Mos IC, Creemers-Schild D, et al. Outpatient treatment in patients with acute pulmonary embolism: the Hestia Study. J Thromb Haemost 2011; 9: 1500-1507.

67 Desai SR. Unsuspected pulmonary embolism on CT scanning: yet another headache for clinicians? Thorax 2007; 62: 470-472.

68 Goodman LR. Small pulmonary emboli: what do we know? Radiology 2005; 234: 654-658.

69 Stein PD, Goodman LR, Hull RD, et al. Diagnosis and management of isolated subsegmental pulmonary embolism: review and assessment of the options. Clin Appl Thromb Hemost 2012; 18: 20-26.

70 den Exter PL, van Es J, Klok FA, et al. Risk profile and clinical outcome of symptomatic subsegmental acute pulmonary embolism. Blood 2013; 122: 1144-1149.

71 Aujesky D, Roy PM, Verschuren F, et al. Outpatient versus inpatient treatment for patients with acute pulmonary embolism: an international, open-label, randomised, non-inferiority trial. Lancet 2011; 378: 41-48.

72 McCabe A, Hassan T, Doyle M, et al. Identification of patients with low-risk pulmonary embolism suitable for outpatient treatment using the pulmonary embolism severity index (PESI). Ir J Med Sci 2013; 182: 291-295.

73 Kovacs MJ, Hawel JD, Rekman JF, et al. Ambulatory management of pulmonary embolism: a pragmatic evaluation. J Thromb Haemost 2010; 8: 2406-2411.

74 Erkens PM, Gandara E, Wells PS, et al. Does the Pulmonary Embolism Severity Index accurately identify low risk patients eligible for outpatient treatment? Thromb Res 2012; 129: 710-714.

75 Zondag W, Kooiman J, Klok FA, et al. Outpatient versus inpatient treatment in patients with pulmonary embolism: a meta-analysis. Eur Respir J 2013; 42: 134-144.

76 Otero R, Uresandi F, Jiménez D, et al. Home treatment in pulmonary embolism. Thromb Res 2010; 126: e1-e5.

77 Stein PD, Beemath A, Matta F, et al. Enlarged right ventricle without shock in acute pulmonary embolism: prognosis. Am J Med 2008; 121: 34-42.

78 Prandoni P, Noventa F, Quintavalla R, et al. Thigh-length versus below-knee compression elastic stockings for prevention of the postthrombotic syndrome in patients with proximal-venous thrombosis: a randomized trial. Blood 2012; 119: 1561-1565.

79 Kahn SR, Shapiro S, Wells PS, et al. Compression stockings to prevent post-thrombotic syndrome: a randomised placebo-controlled trial. Lancet 2014; 383: 880-888.

80 Gavish I, Brenner B. Air travel and the risk of thromboembolism. Intern Emerg Med 2011; 6: 113-116.

$81 \mathrm{Lu} \mathrm{G}$, DeGuzman FR, Hollenbach SJ, et al. A specific antidote for reversal of anticoagulation by direct and indirect inhibitors of coagulation Factor Xa. Nat Med 2013; 19: 446-451.

82 Schiele F, van Ryn J, Canada K, et al. A specific antidote for dabigatran: functional and structural characterization. Blood 2013; 121: 3554-3562.

83 Mueck W, Schwers S, Stampfuss J. Rivaroxaban and other novel oral anticoagulants: pharmacokinetics in healthy subjects, specific patient populations and relevance of coagulation monitoring. Thromb J 2013; 11: 10.

84 National Institute for Health and Clinical Excellence. Rivaroxaban for the treatment of deep vein thrombosis and prevention of recurrent deep vein thrombosis and pulmonary embolism. Technology appraisal 261. www.nice.org. uk/ta261 Date last updated: July, 2012. Date last accessed: October 6, 2014. 